\title{
High expression levels of Wnt5a and Ror2 in laryngeal squamous cell carcinoma are associated with poor prognosis
}

\author{
WEI ZHANG ${ }^{1 *}$, YONGBING YAN $^{1 *}$, MIAO GU $^{1}$, XUDONG WANG $^{2}$, \\ HUIJUN ZHU ${ }^{3}$, SHU ZHANG ${ }^{3}$ and WEI WANG ${ }^{3}$ \\ Departments of ${ }^{1}$ Otorhinolaryngology, ${ }^{2}$ Surgical Comprehensive Laboratory and ${ }^{3}$ Clinical Pathology, \\ Affiliated Hospital of Nantong University, Nantong, Jiangsu 226001, P.R. China
}

Received September 9, 2015; Accepted March 30, 2017

DOI: $10.3892 / \mathrm{ol} .2017 .6386$

\begin{abstract}
The present study investigated the prognostic significance of Wnt family member 5a (Wnt5a) and receptor tyrosine kinase-like orphan receptor 2 (Ror2) expression in laryngeal squamous cell carcinoma (LSCC). The protein expression levels of Wnt5a and Ror2 were analyzed in specimens from 137 patients with LSCC, using immunohistochemical staining of tissue microarrays and pairs of LSCC and adjacent tissue samples, and examined the associations between the two markers and various clinicopathological parameters. The Wnt5a and Ror2 expression levels were significantly higher in LSCC tissues than in normal tissue samples (Wnt5a, $\mathrm{P}=0.015$; Ror2, $\mathrm{P}=0.039)$, and were significantly associated with high tumor stage $(\mathrm{P}<0.001)$, lymph node metastasis (Wnt5a, $\mathrm{P}=0.029$; Ror2, $\mathrm{P}=0.018)$, and with each other $(\mathrm{P}=0.002)$. Patients with LSCC with high Wnt5a or Ror2 expression had poorer prognosis compared with those with low Wnt5a $(\mathrm{P}=0.022)$ or Ror2 $(\mathrm{P}=0.038)$ expression. Thus, Wnt5a and Ror2 may affect LSCC development, and are potential biomarkers in LSCC.
\end{abstract}

\section{Introduction}

Laryngeal squamous cell carcinoma (LSCC) is a common type of head and neck malignancy, and is also the second most common malignancy of the respiratory tract $(1,2)$. The prognosis of LSCC is associated with the primary site, clinical stage, pathological differentiation and lymph node metastasis (3).

Correspondence to: Professor Miao Gu, Department of Otorhinolaryngology, Affiliated Hospital of Nantong University, 20 Xisi Road, Nantong, Jiangsu 226001, P.R. China

E-mail: 13862932120@163.com

${ }^{*}$ Contributed equally

Key words: Wnt family member 5a, receptor tyrosine kinase-like orphan receptor 2, laryngeal squamous cell carcinoma, immunohistochemistry, prognosis
Despite advancements in the available treatments for LSCC, its survival rate has not improved significantly. Therefore, the identification of cancer-associated biomarkers is warranted to diagnose LSCC and improve its prognosis.

Wnt proteins, a large family of cysteine-rich, secreted molecules, function by activating various intracellular signaling pathways (4). Wnt interactions are classified as belonging to the canonical or non-canonical pathways $(5,6)$. The canonical pathway is $\beta$-catenin-dependent (4), whereas the non-canonical pathway is $\beta$-catenin-independent, and includes planar cell polarity (PCP) and $\mathrm{Wnt} / \mathrm{Ca}^{2+}$ signaling pathways (5). Mutations of the canonical Wnt signaling pathway have been demonstrated to be associated with head and neck carcinogenesis, particularly in oral cancer (7). However, the role of the Wnt signaling pathway specifically in LSCC remains unclear.

Wnt family member 5a (Wnt5a) is a Wnt ligand that affects almost all aspects of the non-canonical pathway (8-10). Wnt5a has an important role in the progression of malignancies; for example, in head and neck squamous cell carcinoma (HNSCC), it has been reported that Wnt5a is highly expressed and may act as a tumor promoter $(11,12)$. However, its role varies in different types of cancer, and its function is significantly altered by its receptors (13-15). Receptor tyrosine kinase-like orphan receptor 2 (Ror2) mediates the Wnt5a-dependent non-canonical pathway, and is required for Wnt5a-mediated inhibition of the canonical pathway $(16,17)$.

Ror2, an orphan tyrosine kinase, is characterized by intracellular tyrosine kinase domains (related to those of the Trk-family receptor tyrosine kinases), extracellular Frizzled (Fz)-like cysteine-rich domains (CRD), and membrane-proximal Kringle domains $(18,19)$. Ror2 affects diverse cellular processes, including the cell cycle, cell proliferation, differentiation and migration (18). As the receptor for Wnt5a, Ror2 mediates the PCP pathway and inhibits the $\beta$-catenin/T-cell factor (TCF) pathway (16). Ror2 is reportedly overexpressed in renal cell carcinoma, squamous cell carcinoma and metastatic melanoma (20-22), but downregulated in hepatocellular carcinoma, medulloblastoma, and colon cancer (23-25). Accordingly, as with Wnt5a, the functions of Ror2 vary depending on the cancer type and signaling pathway.

To the best of our knowledge, the roles of Wnt5a/Ror 2 in the non-canonical pathway in LSCC have not been previously investigated. Thus in the present study, the expression and 
clinical significance of Wnt5a and Ror2 were investigated in LSCC.

\section{Materials and methods}

Patient selection and data collection. A total of 137 LSCC tissue samples and 28 adjacent non-tumor tissues were collected from a cohort of laryngeal carcinoma patients following surgical excision at the Department of Otolaryngology, Head and Neck Surgery, Affiliated Hospital of Nantong University (Nantong, China) between January 2005 and December 2013. The patients included 130 males and 7 females aged 46-80 years old (mean age, 66.8 years). All patients were diagnosed with LSCC according to the World Health Organization criteria (26) and Tumor Node Metastasis (TNM) classification (Union for International Cancer Control, 2009). Patients underwent laryngectomy and neck dissection (unilateral or bilateral, radical or functional, based on clinical and surgical findings) at the Affiliated Hospital of Nantong University (Nantong, China). No patients had received radiation therapy, chemotherapy or immunotherapy prior to surgery. The present study was approved by the Ethics Committee of the Affiliated Hospital of Nantong University and written informed consent was obtained from all patients.

Tissue microarray (TMA). In the current study, 137 formalin-fixed paraffin-embedded LSCC and 28 tumor-adjacent normal tissue samples were prepared as TMAs, which were generated using a manual Tissue Microarrayer Quick-Ray system (UT06; Unitma Co., Ltd., Seoul, Korea). A total of three TMAs were produced, whereby $4-\mu \mathrm{m}$ sections were cut and placed on Superfrost charged glass microscope slides.

Immunohistochemistry (IHC). The TMA slides for IHC were deparaffinized and rehydrated through an alcohol gradient. Endogenous peroxidase activity was blocked through incubation of slides in $3 \% \mathrm{H}_{2} \mathrm{O}_{2}$ at room temperature for $15 \mathrm{~min}$. Antigen retrieval was performed by incubation with citrate buffer ( $\mathrm{pH} \mathrm{6.0)}$ at $95^{\circ} \mathrm{C}$ for $15 \mathrm{~min}$. Wnt5a expression was detected using a mouse monoclonal anti-human Wnt5a primary antibody (dilution, 1:200; cat no. ab110073; Abcam, Cambridge, UK), and Ror2 was detected using a rabbit polyclonal anti-human Ror2 primary antibody (dilution, 1:100; cat no. LS-C99125; Lifespan BioSciences, Inc., Seattle, WA, USA), which were incubated at $4^{\circ} \mathrm{C}$ overnight. Then reactions were detected with EnVision ${ }^{\mathrm{TM}}+$ Peroxidase kit (no. K165212F; Dako; Agilent Technologies, Inc., Santa Clara, CA, USA) at room temperature for $30 \mathrm{~min}$. Sections were stained with 3,3'-diaminobenzidine (Dako; Agilent Technologies, Inc.), counterstained with hematoxylin, dehydrated through an alcohol gradient, cleared with xylene and cover-slipped with permanent mounting media using a previously described protocol $(27,28)$.

Results were determined using a double-blind method by two investigators. The results were reevaluated by a third investigator when disagreement between the primary two investigators occurred, until a consensus was established. Expression levels of Wnt5a and Ror2 were assessed by observing the incidence and staining intensity of IHC-stained cells. The intensity of staining was scored as follows: 0, no staining; 1 , weak positive; 2 , moderate positive; and 3 , strong positive. The final staining score was estimated by multiplying the staining intensity score by the staining area percentage, producing a score in the range of 0 (no staining) to $300(100 \%$ of cells with strong staining), following a previously described method (29).

Statistical analysis. For statistical analysis, continuous Wnt5a and Ror2 expression data from LSCC were first converted into dichotomized data (low vs. high) using specific cutoff values, which were assessed with regard to their ability to predict overall survival (OS) using the X-tile software program (Rimm Lab, Yale University, New Haven, CT, USA; http://www.tissuearray.org/rimmlab) (29-31). Using the X-tile software program for TMA data analysis (http://www. tissuearray.org/rimmlab), we first identified significant cutoff point in terms of OS in LSCC. For Wnt5a, the cutoff 180 was selected: Score 0-180 was considered low expression, while 180-300 was considered high expression. For Ror2, the cutoff point 192 was selected: Score 0-192 was considered low expression, while 192-300 was considered high expression. For all subsequent analyses, Wnt5a and Ror2 protein expression levels were considered either as 'low' or 'high' using these cutoff values.

Statistical analysis was performed using SPSS software (version 20.0; IBM Corp., Armonk, NY, USA). Pearson's $\chi^{2}$ test was used to analyze differences in Wnt5a and Ror2 expression in LSCC and adjacent normal tissue samples, and the correlations between the two markers and clinicopathological parameters. Survival curves were calculated using the Kaplan-Meier estimator method and the log-rank test was used for statistical analysis. Univariate and multivariate analyses were performed using Cox's regressions models. $\mathrm{P}<0.05$ was considered to indicate a statistically significant difference.

\section{Results}

Wnt5a and Ror2 expression in LSCC tissue. Wnt5a and Ror2 protein were localized in the cytoplasm (Fig. 1). The frequencies of high Wnt5a expression $(\mathrm{P}=0.015)$ and high Ror2 expression $(\mathrm{P}=0.039)$ were significantly higher in LSCC tissues compared with those in tumor-adjacent normal tissue samples (Table I). Notably, high Wnt5a and Ror2 coexpression (Wnt $5 \mathrm{a}^{+} /$Ror $2^{+}$) was only detected in LSCC tissue, although not all LSCC samples exhibited coexpression of Wnt5a and Ror2.

Association between Wnt5a and Ror2 expression and clinicopathological characteristics in LSCC. In the present study, the associations between Wnt5a or Ror 2 protein expression and clinical parameters among patients with LSCC were examined. High Wnt5a and high Ror2 expression levels were significantly associated with TNM stage (III/IV vs. I/II; both $\mathrm{P}<0.001$ ) and lymph node metastasis (Wnt5a, $\mathrm{P}=0.029$; Ror2, $\mathrm{P}=0.018$; Table II). High $\mathrm{Wnt} 5 \mathrm{a}^{+} / \mathrm{Ror}^{+}$coexpression was significantly associated with high TNM stage $(\mathrm{P}<0.001)$. In addition, a significant and positive correlation between Wnt5a and Ror2 expression was detected ( $\mathrm{P}=0.002$; Table II). 


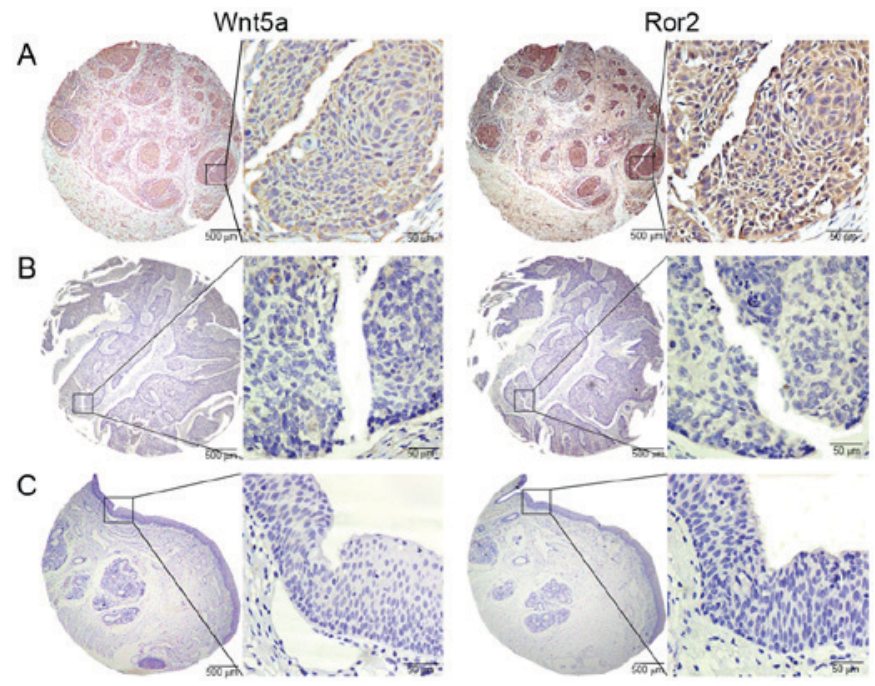

Figure 1. Representation of Wnt5a and Ror 2 protein expression in LSCC and tumor-adjacent normal tissue on tissue microarray sections. (A) LSCC with high Wnt5a and Ror2 expression. (B) LSCC with no Wnt5a or Ror2 expression. (C) Tumor-adjacent normal tissue with no Wnt5a expression or Ror 2 expression. Wnt5a and Ror2 staining are each shown at $\mathrm{x} 40$ and x400 magnification, with hematoxylin counterstaining. Wnt5a, Wnt family member 5a; Ror2, receptor tyrosine kinase-like orphan receptor 2; LSCC, laryngeal squamous cell carcinoma.

Prognostic value of Wnt5a and Ror2 protein expression in LSCC. Prognostic factors in LSCC were determined using univariate and multivariate analyses. High Wnt5a expression $(\mathrm{P}=0.022)$, high Ror2 expression $(\mathrm{P}=0.002)$ and high Wnt $5 \mathrm{a}^{+} /$Ror $^{+}$coexpression $(\mathrm{P}<0.001)$ were significantly associated with poor OS according to univariate analysis. In addition, sex $(\mathrm{P}=0.003)$, TNM stage $(\mathrm{P}=0.028)$, lymph node metastasis $(\mathrm{P}=0.013)$ and high histopathological grade $(\mathrm{P}=0.011)$ were significantly associated with poor OS in the univariate analysis. Following multivariate analysis, high Wnt5a [hazard ratio (HR), 2.540; 95\% confidence interval (CI), 1.146-5.630; $\mathrm{P}=0.022$ ] and high Ror2 (HR, 2.290; 95\% CI, 1.049-5.000; $\mathrm{P}=0.038$ ) expression remained significantly associated with poor OS (Table III). The Kaplan-Meier analyses revealed that patients in the high Wnt5a expression group $\left(\mathrm{Wnt} 5 \mathrm{a}^{+}\right.$) had significantly poorer prognosis compared with those in the low-expression group (Wnt5a; P=0.020; Fig. 2A), and patients in the high Ror2 expression group $\left(\right.$ Ror $\left.2^{+}\right)$also had significantly poorer prognosis compared with those in the low-expression group (Ror2; $\mathrm{P}=0.001$; Fig. 2B). More importantly, patients in the high Wnt5a and high Ror2 expression level group (Wnt5 $\mathrm{a}^{+} /$Ror $^{+}$) demonstrated significantly poorer prognosis compared with those in the high Wnt5a or high Ror2 expression level group (Wnt $5 \mathrm{a}^{+} /$Ror 2 or Wnt5a $/$ Ror $2^{+}$) and those in the low-expression group (Wnt5a/Ror2; P=0.001; Fig. 2C).

\section{Discussion}

To the best of our knowledge, the present study is the first to investigate Wnt5a and Ror2 protein expression and their prognostic value in LSCC. The results demonstrated that Wnt5a and Ror2 protein expression levels are significantly higher in LSCC compared with in adjacent normal tissue samples. High 


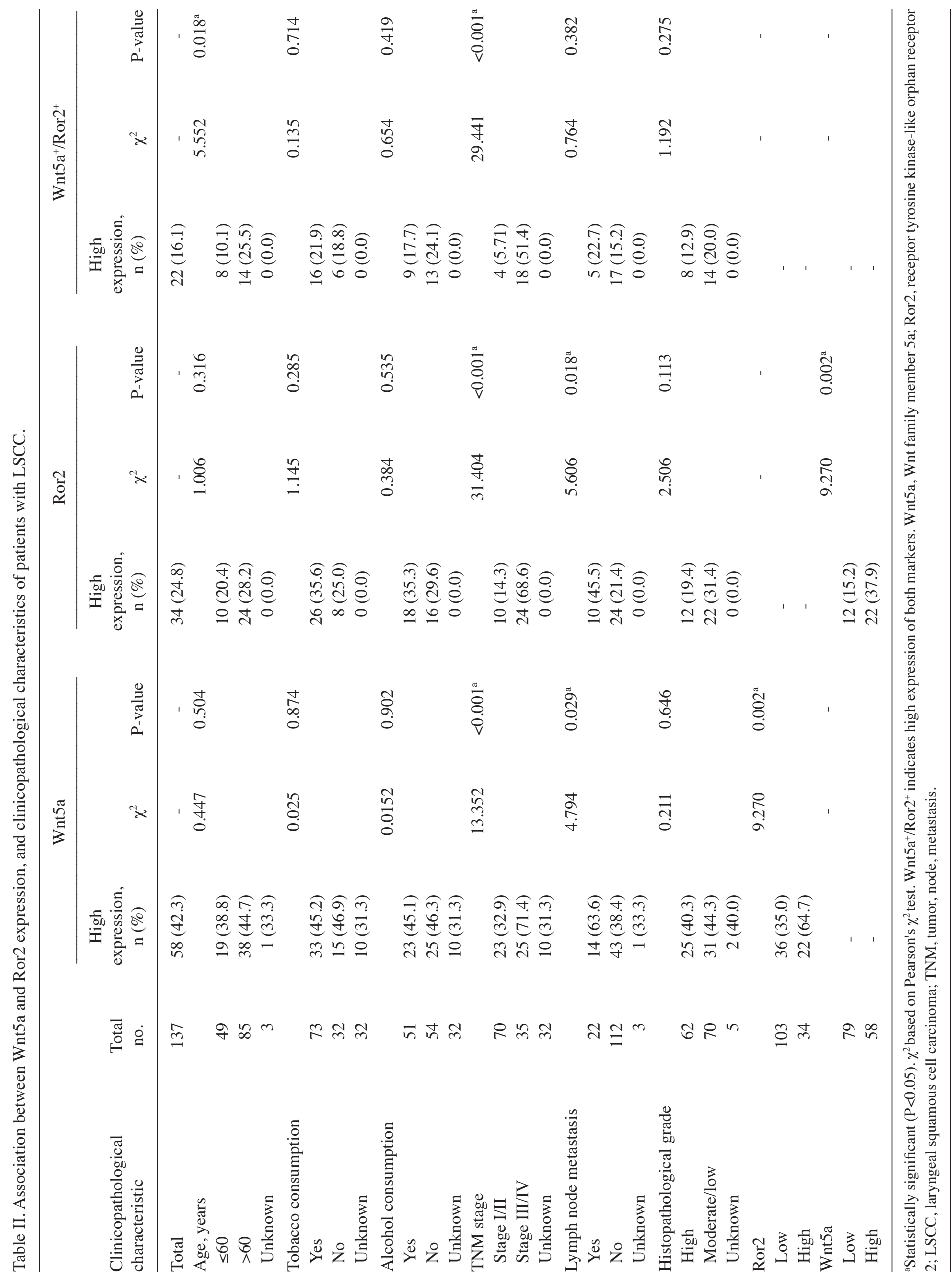


Table III. Univariate and multivariate analyses of prognostic factors for overall survival in LSCC.

\begin{tabular}{|c|c|c|c|c|c|c|}
\hline \multirow[b]{2}{*}{ Factor } & \multicolumn{3}{|c|}{ Univariate analysis } & \multicolumn{3}{|c|}{ Multivariate analysis } \\
\hline & P-value & $\mathrm{HR}$ & $95 \% \mathrm{CI}$ & P-value & HR & $95 \% \mathrm{CI}$ \\
\hline Wnt5a expression: High vs. low & $0.022^{\mathrm{a}}$ & 2.092 & $0.254-0.901$ & $0.022^{\mathrm{a}}$ & 2.540 & $1.146-5.630$ \\
\hline Ror2 expression: High vs. low & $0.002^{\mathrm{a}}$ & 2.746 & $1.462-5.158$ & $0.038^{\mathrm{a}}$ & 2.290 & $1.049-5.000$ \\
\hline Wnt $5 \mathrm{a}^{+} /$Ror $^{+}$vs. non-Wnt $5 \mathrm{a}^{+} /$Ror $^{+}$ & $<0.001^{\mathrm{a}}$ & 3.285 & $1.683-6.411$ & - & - & - \\
\hline Gender: Male vs. female & $0.003^{\mathrm{a}}$ & 0.106 & $0.025-0.454$ & $0.001^{\mathrm{a}}$ & 0.047 & $0.008-0.264$ \\
\hline Age, years: $\leq 60$ vs. $>60$ & 0.274 & 1.463 & $0.740-2.891$ & 0.209 & 1.762 & $0.728-4.264$ \\
\hline Tobacco consumption: Yes vs. no & 0.303 & 0.687 & $0.336-1.404$ & 0.187 & 0.518 & $0.195-1.375$ \\
\hline Alcohol consumption: Yes vs. no & 0.476 & 0.787 & $0.408-1.520$ & 0.826 & 0.905 & $0.372-2.200$ \\
\hline TNM stage: III/IV vs. I/II & $0.028^{\mathrm{a}}$ & 2.084 & $1.083-4.010$ & 0.649 & 0.823 & $0.355-1.906$ \\
\hline Lymph node metastasis: Yes vs. no & $0.013^{\mathrm{a}}$ & 2.428 & $1.202-4.904$ & $0.002^{\mathrm{a}}$ & 3.899 & $1.647-9.229$ \\
\hline Histopathological grade: High vs. moderate/low & $0.011^{\mathrm{a}}$ & 2.423 & $1.226-4.788$ & 0.164 & 1.706 & $0.804-3.619$ \\
\hline
\end{tabular}

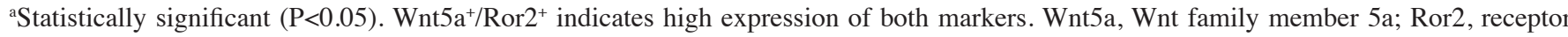
tyrosine kinase-like orphan receptor 2; LSCC, laryngeal squamous cell carcinoma; TNM, tumor-node-metastasis; HR, hazard ratio; CI, confidence interval.
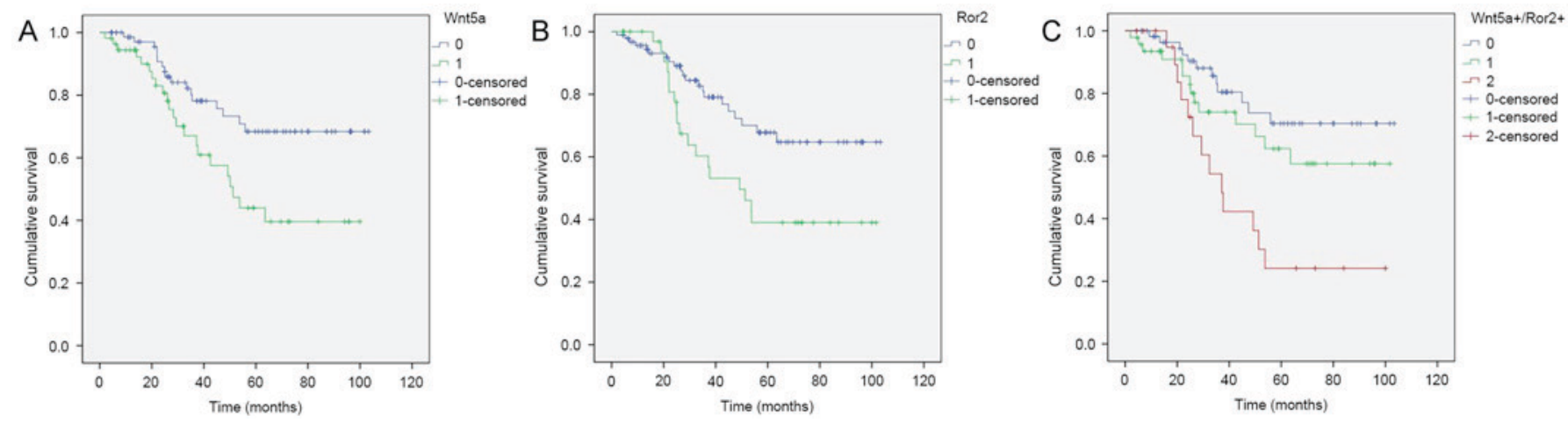

Figure 2. Survival curves of laryngeal squamous cell carcinoma determined using the Kaplan-Meier estimator method and the log-rank test. Overall

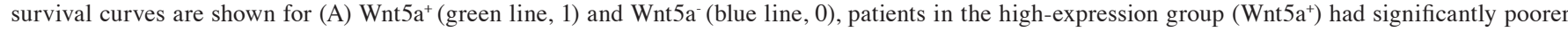
prognosis compared with those in the low-expression group (Wnt5a; $\mathrm{P}=0.020, \log$-rank test); (B) Ror2 ${ }^{+}$(green line, 1) and Ror2- (blue line, 0 ), patients in the high-expression group $\left(\right.$ Ror2 $2^{+}$) had significantly poorer prognosis compared with those in the low-expression group (Ror2; $\mathrm{P}=0.001$, log-rank test); and

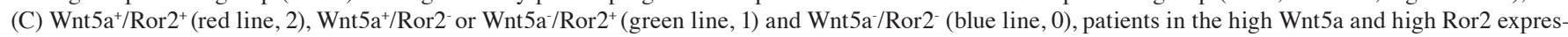
sion group $\left(\mathrm{Wnt}_{5} \mathrm{a}^{+} / \mathrm{Ror}^{+}\right.$) had significantly poorer prognosis compared with both those in the high Wnt5a or high Ror 2 expression group (Wnt5a $/$ Ror2 or Wnt5a $/$ Ror $^{+}$) and those in the low-expression group (Wnt5a/Ror2; $\mathrm{P}=0.001$, log-rank test). Wnt5a, Wnt family member 5a; Ror2, receptor tyrosine kinase-like orphan receptor 2 .

Wnt5a and Ror2 protein expression levels were associated with high TNM stage and lymph node metastasis. Furthermore, a positive correlation was identified between Wnt5a and Ror2 expression. Univariate and multivariate analyses revealed that high Wnt5a and Ror2 expression were significantly associated with poor OS.

Wnt5a, a member of Wnt family, is located at the chromosomal site 3p14.2-p21.1, which was revealed by Clark et al (32). Wnt5a interacts with G-proteins to activate the non-canonical Wnt $/ \mathrm{Ca}^{2+}$ pathway. This signaling pathway can activate or inhibit the canonical Wnt/ $\beta$-catenin pathway, depending on the interaction of Wnt5a with various receptors. For example, when Wnt5a interacts with Ror2, the Wnt/ $\beta$-catenin pathway is inhibited. Conversely, when Wnt5a combines with $\mathrm{Fz}$ or low-density lipoprotein receptor-related protein, the
Wnt/ $\beta$-catenin pathway is activated (33). Wnt5a affects cell proliferation, migration, invasion and angiogenesis, and is also involved in the genesis and development of various types of carcinoma through its combination with different receptors $(34,35)$. In the present study, Wnt5a protein expression was identified to be significantly higher in LSCC compared with in adjacent normal tissue samples. Thus, Wnt5a may act as a tumor promoter for LSCC. Similar results have been observed in non-small cell lung carcinoma, metastatic melanoma and gastric cancer $(15,36,37)$. Furthermore, the current study investigated the associations of Wnt5a and Ror2 protein expression with OS in 137 patients with LSCC. High Wnt5a expression was significantly associated with poor OS on univariate and multivariate analyses, indicating that Wnt5a is an independent prognostic factor, and may be a tumor 
promoter in LSCC. However, previous studies have indicated that Wnt5a is a tumor suppressor in certain types of cancer, including hepatocellular carcinoma, thyroid carcinoma and colon carcinoma $(23,38,39)$. These findings suggest that the Wnt5a-regulated pathways and the functional role of $\mathrm{Wnt} 5 \mathrm{a}$ depend on the cancer cell type.

Ror2 is an orphan tyrosine kinase, belonging to the Ror family and acts as a receptor for Wnt5a (40). The biological function of Ror requires its presence in the cell membrane; however, in the present study, Wnt5a and Ror2 protein were localized in the cytoplasm. Since Ror2 possesses an extracellular CRD that resembles the Wnt-binding sites of the Fz proteins $(41,42)$, it may be assumed that Wnt5a binds to the CRD of Ror2. This hypothesis was confirmed in a study performed by Oishi et al (40), which also demonstrated that Ror2 associated with receptor Fz2, a putative receptor for Wnt5a, via its CRD (43). Ror2 is expressed in the face, limbs, heart and lungs during mouse embryogenesis (44). Mice that lack Ror2 expression exhibit facial abnormalities, dwarfism, short limbs and tails, dysplasia of lungs and genitals, abnormalities in axial skeletons, and ventricular septal defects, resulting in neonatal mortality $(45,46)$. Mutations of Ror2 that result in misfolded protein or premature truncation have been associated with human diseases, including dominant Brachydactyly type B, a dominant skeletal disorder characterized by hypoplasia or aplasia of distal phalanges $(47,48)$; and Robinow syndrome, a recessive condition characterized by short stature, segmental defects of the spine, limb bone shortening, and a dysmorphic facial appearance (49). Thus, Ror2 is essential in embryogenesis. Together, Wnt5a/Ror2 have been revealed to mediate the non-canonical Wnt signal pathway and simultaneously suppress $\mathrm{Wnt} / \beta$-catenin activity. In addition, it has been demonstrated that the Ror2 receptor requires tyrosine kinase activity to mediate the Wnt5a signal pathway $(16,50)$. In the current study, Ror2 protein was highly expressed in LSCC tissue samples. Furthermore, following univariate and multivariate analyses, high Ror2 expression was significantly associated with poor OS, which demonstrated that Ror2 was also an independent prognostic factor, and a possible tumor promoter in LSCC. These results were consistent with previous studies (20-22); however, other studies have demonstrated that Ror2 expression is reduced in hepatocellular carcinoma, medulloblastoma and colon cancer (23-25). Thus, Ror2 may serve different roles in different cancer types, as with Wnt5a.

Wnt5a and Ror2 are important in developmental morphogenesis, particularly in skeletal development $(51,52)$. Notably, Ror ${ }^{-/-}$and $\mathrm{Wnt}_{5} \mathrm{a}^{-/-}$mice exhibit similar defect phenotypes (40). Previous studies have demonstrated that Brachydactyly type B and Robinow syndrome are associated with the non-canonical Wnt5a/Ror2 signaling pathway (53). The current study identified a positive correlation between Wnt5a and Ror2 expression and, these results suggested that Wnt5a and Ror2 may be associated with the development of LSCC.

In conclusion, the overexpression of Wnt5a and Ror2 was detected in LSCC tissue samples, and was significantly associated with tumor stage, lymph node metastasis and poor prognosis of LSCC. These findings provide a novel insight into the mechanisms underlying tumorigenesis and have identified two potential therapeutic targets for LSCC.

\section{References}

1. Siegel R, Naishadham D and Jemal A: Cancer statistics, 2012. CA Cancer J Clin 62: 10-29, 2012.

2. Hoffman HT, Porter K, Karnell LH, Cooper JS, Weber RS, Langer CJ, Ang KK, Gay G, Stewart A and Robinson RA: Laryngeal cancer in the United States: Changes in demographics, patterns of care and survival. Laryngoscope 116 (Suppl 111): S1-S13, 2006.

3. Papadas TA, Alexopoulos EC, Mallis A, Jelastopulu E, Mastronikolis NS and Goumas P: Survival after laryngectomy: A review of 133 patients with laryngeal carcinoma. Eur Arch Otorhinolaryngol 267: 1095-1101,2010.

4. Logan CY and Nusse R: The Wnt signaling pathway in development and disease. Annu Rev Cell Dev Biol 20: 781-810, 2004.

5. Veeman MT, Axelrod JD and Moon RT: A second canon. Functions and mechanisms of beta-catenin-independent Wnt signaling. Dev Cell 5: 367-377, 2003.

6. Korinek V, Barker N, Willert K, Molenaar M, Roose J, Wagenaar G, Markman M, Lamers W, Destree O and Clevers H: Two members of the Tcf family implicated in Wnt/beta-catenin signaling during embryogenesis in the mouse. Mol Cell Biol 18: 1248-1256, 1998 .

7. Molinolo AA, Amornphimoltham P, Squarize $\mathrm{CH}$, Castilho RM, Patel V and Gutkind JS: Dysregulated molecular networks in head and neck carcinogenesis. Oral Oncol 45: 324-334, 2009.

8. Qian D, Jones C, Rzadzinska A, Mark S, Zhang X, Steel KP, Dai $\mathrm{X}$ and Chen P: Wnt5a functions in planar cell polarity regulation in mice. Dev Biol 306: 121-133, 2007.

9. Slusarski DC, Corces VG and Moon RT: Interaction of Wnt and a Frizzled homologue triggers G-protein-linked phosphatidylinositol signalling. Nature 390: 410-413, 1997.

10. Pandur P, Maurus D and Kuhl M: Increasingly complex: New players enter the Wnt signaling network. Bioessays 24: 881-884, 2002.

11. Diaz Prado SM, Medina Villaamil V, Aparicio Gallego G, Blanco Calvo M,López Cedrún JL, Sironvalle Soliva S, Valladares Ayerbes M, García Campelo R and Antón Aparicio LM: Expression of Wnt gene family and frizzled receptors in head and neck squamous cell carcinomas. Virchows Arch 455: 67-75, 2009.

12. Rhee CS, Sen M, Lu D, Wu C, Leoni L, Rubin J, Corr M and Carson DA: Wnt and frizzled receptors as potential targets for immunotherapy in head and neck squamous cell carcinomas. Oncogene 21: 6598-6605, 2002.

13. Giles RH, van Es JH and Clevers H: Caught up in a Wnt storm: Wnt signaling in cancer. Biochim Biophys Acta 1653: 1-24, 2003.

14. Pukrop T and Binder C: The complex pathways of Wnt $5 \mathrm{a}$ in cancer progression. J Mol Med (Berl) 86: 259-266, 2008.

15. McDonald SL and Silver A: The opposing roles of Wnt-5a in cancer. Br J Cancer 101: 209-214, 2009.

16. Mikels AJ and Nusse R: Purified Wnt5a protein activates or inhibits beta-catenin-TCF signaling depending on receptor context. PLoS Biol 4: e115, 2006.

17. MacLeod RJ, Hayes M and Pacheco I: Wnt5a secretion stimulated by the extracellular calcium-sensing receptor inhibits defective Wnt signaling in colon cancer cells. Am J Physiol Gastrointest Liver Physiol 293: G403-G411, 2007.

18. Forrester WC: The Ror receptor tyrosine kinase family. Cell Mol Life Sci 59: 83-96, 2002.

19. Yoda A, Oishi I and Minami Y: Expression and function of the Ror-family receptor tyrosine kinases during development: Lessons from genetic analyses of nematodes, mice, and humans. J Recept Signal Transduct Res 23: 1-15, 2003.

20. Wright TM, Brannon AR, Gordan JD, Mikels AJ, Mitchell C, Chen S, Espinosa I, van de Rijn M, Pruthi R, Wallen E, et al: Ror2, a developmentally regulated kinase, promotes tumor growth potential in renal cell carcinoma. Oncogene 28: 2513-2523, 2009.

21. Kobayashi M, Shibuya Y, Takeuchi J, Murata M, Suzuki H, Yokoo S, Umeda M, Minami Y and Komori T: Ror2 expression in squamous cell carcinoma and epithelial dysplasia of the oral cavity. Oral Surg Oral Med Oral Pathol Oral Radiol Endod 107: 398-406, 2009.

22. O'Connell MP, Fiori JL, Xu M, Carter AD, Frank BP, Camilli TC, French AD, Dissanayake SK, Indig FE, Bernier M, et al: The orphan tyrosine kinase receptor, ROR2, mediates Wnt5A signaling in metastatic melanoma. Oncogene 29: 34-44, 2010 
23. Geng M, Cao YC, Chen YJ, Jiang H, Bi LQ and Liu XH: Loss of Wnt5a and Ror2 protein in hepatocellular carcinoma associated with poor prognosis. World J Gastroenterol 18: 1328-1338, 2012.

24. Lee SE, Lim SD, Kang SY, Suh SB and Suh YL: Prognostic significance of Ror2 and Wnt5a expression in medulloblastoma. Brain Pathol 23: 445-453, 2013.

25. Lara E, Calvanese V, Huidobro C, Fernández AF, Moncada-Pazos A, Obaya AJ, Aguilera O, González-Sancho JM, Sánchez L, Astudillo A, et al: Epigenetic repression of ROR2 has a Wnt-mediated, pro-tumourigenic role in colon cancer. Mol Cancer 9: 170, 2010 .

26. Thompson L: World Health Organization classification of tumours: Pathology and genetics of head and neck tumours. Ear Nose Throat J 85: 74, 2006.

27. Wu H, Xu H, Zhang S, Wang X, Zhu H, Zhang H, Zhu J and Huang J: Potential therapeutic target and independent prognostic marker of TROP2 in laryngeal squamous cell carcinoma. Head Neck 35: 1373-1378, 2013.

28. Feng J, Xu L, Ni S, Gu J, Zhu H, Wang H, Zhang S, Zhang W and Huang J: Involvement of FoxQ1 in NSCLC through regulating EMT and increasing chemosensitivity. Oncotarget 5: 9689-9702, 2014.

29. Wang Q, Ni Q, Wang X, Zhu H, Wang Z and Huang J: High expression of RAB27A and TP53 in pancreatic cancer predicts poor survival. Med Oncol 32: 372, 2015.

30. Ni S, Xu L, Huang J, Feng J, Zhu H, Wang G and Wang X: Increased ZO-1 expression predicts valuable prognosis in non-small cell lung cancer. Int J Clin Exp Pathol 6: 2887-2895, 2013.

31. Sun R, Wang X, Zhu H, Mei H, Wang W, Zhang S and Huang J: Prognostic value of LAMP3 and TP53 overexpression in benign and malignant gastrointestinal tissues. Oncotarget 5 : 12398-12409, 2014.

32. Clark CC, Cohen I, Eichstetter I, Cannizzaro LA, McPherson JD, Wasmuth JJ and Iozzo RV: Molecular cloning of the human proto-oncogene Wnt-5A and mapping of the gene (WNT5A) to chromosome 3p14-p21. Genomics 18: 249-260, 1993.

33. Topol L, Jiang X, Choi H, Garrett-Beal L, Carolan PJ and Yang Y: Wnt-5a inhibits the canonical Wnt pathway by promoting GSK-3-independent beta-catenin degradation. J Cell Biol 162: 899-908, 2003

34. Chen S, Wang J, Gou WF, Xiu YL, Zheng HC, Zong ZH, Takano Y and Zhao Y: The involvement of RhoA and Wnt-5a in the tumorigenesis and progression of ovarian epithelial carcinoma. Int J Mol Sci 14: 24187-24199, 2013.

35. Hudson BD, Kulp KS and Loots GG: Prostate cancer invasion and metastasis: Insights from mining genomic data. Brief Funct Genomics 12: 397-410, 2013

36. Weeraratna AT, Jiang Y, Hostetter G, Rosenblatt K, Duray P, Bittner M and Trent JM: Wnt5a signaling directly affects cell motility and invasion of metastatic melanoma. Cancer Cell 1: 279-288, 2002

37. Kurayoshi M, Oue N, Yamamoto H, Kishida M, Inoue A, Asahara T, Yasui W and Kikuchi A: Expression of Wnt-5a is correlated with aggressiveness of gastric cancer by stimulating cell migration and invasion. Cancer Res 66: 10439-10448, 2006.

38. Kremenevskaja N, von Wasielewski R, Rao AS, Schöfl C, Andersson T and Brabant G: Wnt-5a has tumor suppressor activity in thyroid carcinoma. Oncogene 24: 2144-2154, 2005.

39. Ying J, Li H, Yu J, Ng KM, Poon FF, Wong SC, Chan AT, Sung JJ and Tao Q: WNT5A exhibits tumor-suppressive activity through antagonizing the Wnt/beta-catenin signaling, and is frequently methylated in colorectal cancer. Clin Cancer Res 14: 55-61, 2008.
40. Oishi I, Suzuki H, Onishi N, Takada R, Kani S, Ohkawara B, Koshida I, Suzuki K, Yamada G, Schwabe GC, et al: The receptor tyrosine kinase Ror2 is involved in non-canonical Wnt5a/JNK signalling pathway. Genes Cells 8: 645-654, 2003.

41. Masiakowski P and Yancopoulos GD: The Wnt receptor CRD domain is also found in MuSK and related orphan receptor tyrosine kinases. Curr Biol 8: R407, 1998.

42. Rehn M, Pihlajaniemi T, Hofmann K and Bucher P: The frizzled motif: In how many different protein families does it occur? Trends Biochem Sci 23: 415-417, 1998.

43. He X, Saint-Jeannet JP, Wang Y, Nathans J, Dawid I and Varmus H: A member of the Frizzled protein family mediating axis induction by Wnt-5A. Science 275: 1652-1654, 1997.

44. Matsuda T, Nomi M, Ikeya M, Kani S, Oishi I, Terashima T, Takada $\mathrm{S}$ and Minami Y: Expression of the receptor tyrosine kinase genes, Ror1 and Ror2, during mouse development. Mech Dev 105: 153-156, 2001

45. DeChiara TM, Kimble RB, Poueymirou WT, Rojas J, Masiakowski P, Valenzuela DM and Yancopoulos GD: Ror2, encoding a receptor-like tyrosine kinase, is required for cartilage and growth plate development. Nat Genet 24: 271-274, 2000

46. Takeuchi S, Takeda K, Oishi I, Nomi M, Ikeya M, Itoh K, Tamura S, Ueda T, Hatta T, Otani H, et al: Mouse Ror2 receptor tyrosine kinase is required for the heart development and limb formation. Genes Cells 5: 71-78, 2000.

47. Oldridge M, Fortuna AM, Maringa M, Propping P, Mansour S, Pollitt C, DeChiara TM, Kimble RB, Valenzuela DM, Yancopoulos GD and Wilkie AO: Dominant mutations in ROR2, encoding an orphan receptor tyrosine kinase, cause brachydactyly type B. Nat Genet 24: 275-278,2000.

48. Schwabe GC, Tinschert S, Buschow C, Meinecke P, Wolff G, Gillessen-Kaesbach G, Oldridge M, Wilkie AO, Kömec R and Mundlos S: Distinct mutations in the receptor tyrosine kinase gene ROR2 cause brachydactyly type B. Am J Hum Genet 67: $822-831,2000$.

49. Afzal AR, Rajab A, Fenske CD, Oldridge M, Elanko N, Ternes-Pereira E, Tüysüz B, Murday VA, Patton MA, Wilkie AO and Jeffery S: Recessive Robinow syndrome, allelic to dominant brachydactyly type B, is caused by mutation of ROR 2 . Nat Genet 25: 419-422, 2000

50. Mikels A, Minami Y and Nusse R: Ror2 receptor requires tyrosine kinase activity to mediate Wnt5A signaling. J Biol Chem 284: 30167-30176, 2009.

51. Lyashenko N, Weissenböck M, Sharir A, Erben RG, Minami Y and Hartmann C: Mice lacking the orphan receptor rorl have distinct skeletal abnormalities and are growth retarded. Dev Dyn 239: 2266-2277, 2010.

52. Person AD, Beiraghi S, Sieben CM, Hermanson S, Neumann AN, Robu ME, Schleiffarth JR, Billington CJ Jr, van Bokhoven H, Hoogeboom JM, et al: WNT5A mutations in patients with autosomal dominant Robinow syndrome. Dev Dyn 239: 327-337, 2010.

53. Minami Y, Oishi I, Endo M and Nishita M: Ror-family receptor tyrosine kinases in noncanonical Wnt signaling: Their implications in developmental morphogenesis and human diseases. Dev Dyn 239: 1-15, 2010. 